\title{
Long-term effects of bosentan on quality of life, survival, safety and tolerability in pulmonary arterial hypertension related to connective tissue diseases
}

\author{
C P Denton, ${ }^{1}$ J E Pope, ${ }^{2}$ H-H Peter, ${ }^{3}$ A Gabrielli, ${ }^{4}$ A Boonstra, ${ }^{5}$ F H J van den Hoogen, ${ }^{6}$ \\ G Riemekasten, ${ }^{7}$ S De Vita, ${ }^{8}$ A Morganti, ${ }^{9}$ M Dölberg, ${ }^{9}$ O Berkani, ${ }^{9}$ L Guillevin, ${ }^{10}$ \\ (on behalf of the TRacleer Use in PAH associated with Scleroderma and Connective \\ Tissue Diseases (TRUST) Investigators)
}

\begin{abstract}
${ }^{1}$ Royal Free Hospital, London, UK; ${ }^{2}$ St Joseph's Healthcare, London, Ontario, Canada; ${ }^{3}$ Med. Universitätsklinik Freiburg, Freiburg, Germany; ${ }^{4}$ Azienda Ospedaliera Umberto I, Ancona, Italy; ${ }^{5}$ Vrije Universteit Medisch Centrum, Amsterdam, The Netherlands: ${ }^{6}$ Universitair Medisch Centrum St. Radboud, Nijmegen, The Netherlands; ${ }^{7}$ Charité Universitätsmedizin Berlin, Germany; ${ }^{8}$ Rheumatology Clinic, DPMSC, Azienda Ospedaliero Universitaria, Udine, Italy; ${ }^{9}$ Actelion Pharmaceuticals Ltd., Allschwil, Switzerland;

${ }^{10}$ Hopital Cochin, Paris, France
\end{abstract}

Correspondence to:

C Denton, Center for

Rheumatology, Royal Free

Hospital, Pond Street,

Rheumatology Unit, Lower

Ground Floor, London NW3 20G,

UK; c.denton@medsch.ucl.ac.uk

Accepted 25 November 2007

Published Online First

30 November 2007

\section{UNLOCKED}

This paper is freely available online under the BMJ Journals unlocked scheme, see http:// ard.bmi.com/info/unlocked.dtl

\begin{abstract}
Objectives: This study investigated the long-term effects of bosentan, an oral endothelin $E T_{A} / E T_{B}$ receptor antagonist, in patients with pulmonary arterial hypertension (PAH) exclusively related to connective tissue diseases (CTD)

Methods: A total of 53 patients with $\mathrm{PAH}$ related to connective tissue diseases (PAH-CTD) in World Health Organization (WHO) functional class III received bosentan $62.5 \mathrm{mg}$ twice a day for 4 weeks and then $125 \mathrm{mg}$ twice a day for 44 weeks in this open non-comparative study. Assessments at weeks 16 and 48 included WHO class, clinical worsening, quality of life (Short-Form Health Survey (SF-36) and health assessment questionnaire (HAO) modified for scleroderma), and survival (week 48 only). Safety and tolerability were monitored throughout the study.
\end{abstract}

Results: At week 48, WHO class improved in $27 \%$ of patients (95\% Cl 16-42\%) and worsened in 16\% $195 \% \mathrm{Cl}$ 7-29\%). Kaplan-Meier estimates were 68\% (95\% Cl 55$82 \%)$ for absence of clinical worsening and $92 \%(95 \% \mathrm{Cl}$ 85-100\%) for survival. Overall changes in quality of life were minimal. There were no unexpected side effects observed during the study.

Conclusions: In most patients, bosentan was associated with improvement or stability of clinical status. The $92 \%$ estimate for survival at 48 weeks is a significant achievement in this patient population.

Pulmonary arterial hypertension (PAH) is a progressive and often fatal complication of connective tissue diseases (CTDs) such as systemic sclerosis (SSc), systemic lupus erythaematosus (SLE), and overlap or mixed connective tissue disease (MCTD) ${ }^{1-3}$ CTDs are disorders characterised by a wide range of vascular, inflammatory, and fibrotic manifestations in many organs including lung, kidney, and skin. Over the past decade, advances in medical treatment have improved the management of the complications associated with CTDs. Patients with SLE have benefited from immunosuppressive treatments, ${ }^{4}$ while improved management of the specific complications associated with SSc and MCTD (eg, scleroderma renal crisis), has improved prognosis. ${ }^{5}$ However, PAH remains a major cause of long-term morbidity and mortality. The reported symptomatic $\mathrm{PAH}$ prevalence measured by right heart catheterisation is $8-12 \%$ in patients with SSc, ${ }^{16} 6-11 \%$ in patients with SLE, ${ }^{78}$ and up to $10-45 \%$ in patients with $\mathrm{MCTD}^{3}$ as measured by echocardiography and/or right heart catheterisation.

In these patients, early detection of PAH and a multidisciplinary approach to diagnosis and treatment in specialised PAH and/or CTD centres may improve clinical outcome. ${ }^{910}$ Therapeutic approaches for PAH-CTD are based on those used for treating idiopathic PAH (iPAH). ${ }^{11}$ Anticoagulation, diuretics, and oxygen supplementation are often used although the benefit of this supportive therapy has not been demonstrated in PAH-CTD. ${ }^{1}$ Prostacyclin analogues may improve exercise capacity and pulmonary haemodynamics in these patients. ${ }^{12-15}$ However, despite treatment, patients with PAH-CTDs are functionally impaired with a decreased health status and a poor prognosis. In the absence of concomitant $\mathrm{PAH}$, survival of patients with SSc exceeds $90 \%$ at 1 year $^{16}{ }^{17}$ but once PAH has been diagnosed, it decreases to $50 \%,{ }^{18}{ }^{19}$ which is worse than for patients with iPAH (84\%). ${ }^{19}$ The risk of death from PAH related to $\mathrm{SSc}$ is threefold higher than from iPAH. ${ }^{19}$

Bosentan is an oral dual $\left(\mathrm{ET}_{\mathrm{A}}\right.$ and $\left.\mathrm{ET}_{\mathrm{B}}\right)$ endothelin-1 receptor antagonist. In placebo-controlled clinical trials and in long-term extension studies, ${ }^{20-22}$ bosentan was well tolerated, improved exercise capacity and haemodynamics, and delayed the time to clinical worsening in patients with iPAH and PAH-CTD. Survival estimates at 1 and 2 years were $86 \%$ and $73 \%$, respectively, in a subgroup analysis of patients with PAH-CTD. ${ }^{23}$ Improvement in quality of life (SF-36 instrument) has been reported after 3 and 6 months of bosentan treatment in patients with iPAH and PAH-CTD (59\% and 41\%, respectively) participating in the VITAL study. ${ }^{24}$ However, changes in health-related quality of life have not been assessed together with survival. Since the concomitant assessment of these two aspects is critical to appreciate overall outcome, the present multicentre European study was designed to investigate changes in health-related quality of life together with survival over a 48-week observation period in patients with PAH exclusively related to CTD.

\section{PATIENTS AND METHODS \\ Patients}

Included patients (over 18 years of age) had PAH in World Health Organization (WHO) functional class III $^{25}$ related to diffuse or limited SSc, 
MCTD, or SLE (other CTDs were excluded). PAH was confirmed in all patients by right heart catheterisation requiring mean pulmonary artery pressure $\geqslant 25 \mathrm{mmHg}$ at rest, pulmonary vascular resistance $>3$ Wood units, and pulmonary capillary wedge pressure $<15 \mathrm{mmHg} .{ }^{26}$ This catheterisation was performed within 6 months prior to the start of bosentan therapy. Signs of right heart failure, if present at baseline, were required to be stable and patients were required to have received adequate diuretics treatment prior to bosentan initiation. Total lung capacity (TLC) was required to be above $50 \%$ of predicted, to exclude patients with severe interstitial lung disease. Patients were also excluded if they had received any $\mathrm{PAH}$ treatments (except anticoagulants) within 1 month of screening, if they were receiving or were expected to receive epoprostrenol or prostacyclin analogues for more than 2 consecutive weeks, or if they had received glibenclamide, cyclosporin A, or tacrolimus within 1 week of screening. Selective phosphodiesterase inhibitors and endothelin receptor antagonists other than bosentan were not allowed during the study. Disease-modifying antirheumatic drugs (DMARDs) were allowed provided the patient had been stable on treatment for 3 months prior to bosentan initiation.

The study was conducted according to the most recent amendments to the Declaration of Helsinki, and in adherence to Good Clinical Practice guidelines. Local institutional review boards or independent ethics committees approved the protocol. Written informed consent was obtained from all patients.

\section{Study design and procedures}

The study was a prospective single-arm trial and was conducted in 23 centres in 8 European countries. Patients received bosentan $62.5 \mathrm{mg}$ twice a day for 4 weeks followed by the $125 \mathrm{mg}$ twice a day target dose for 44 weeks, in addition to stable antirheumatic treatment. Patients who did not tolerate the $125 \mathrm{mg}$ twice a day target dose were down titrated to the starting dose.

Patients were evaluated on an outpatient basis at baseline and at weeks 4, 8, 16, 24, 36, and 48 or at premature withdrawal. Efficacy assessments included the change from baseline to weeks 16 and 48 in WHO functional class, the time from baseline to clinical worsening (defined as the combined endpoint of death or hospitalisation due to $\mathrm{PAH}$ complications, use of epoprostenol or prostacyclin analogues for worsening of $\mathrm{PAH}$, lung transplantation, discontinuation due to worsening of $\mathrm{PAH}$ ), and the time to death.

Health-related quality of life and disability were evaluated at baseline and week 48, with a generic instrument (the Medical Outcomes Study 36-Item Short-Form Health Survey (SF-36) $)^{27}$ and a disease-specific instrument (the scleroderma modified Health Assessment Questionnaire (HAQ)) ${ }^{28}$ Both instruments have been validated in a variety of chronic diseases including $\mathrm{SSc}^{28-32}$ and SLE. ${ }^{33} 34$

In the SF-36 questionnaire, 35 items cover 8 domains of health: physical functioning, role limitation caused by physical functioning, bodily pain, general health perceptions, vitality, social functioning, role limitation caused by emotional problems, and mental health. The patient's responses are first reported on a scale from 0 to 100 (higher score indicates better health-related quality of life) for each domain following item weighing and additive scaling, these eight scale scores (0-100) are finally transformed (using a linear z-score transformation) to correspond to a mean of 50 and standard deviation of 10 in the 1998 general US population (norm-based scale scores). A 36th item (health transition) asks respondents about any health changes over the past year using five assessment categories, "much better" (category 1), "somewhat better" (category 2), "about the same" (category 3), "somewhat worse" (category 4), and "much worse" (category 5).

The HAQ assessment includes 20 questions in 8 domains of functional activities: dressing, rising, eating, walking, hygiene, reach, grip, and usual activities. The patient's responses are reported on an ordinal scale from 0 (no disability) to 3 (complete disability). The HAQ disability index is the average score across the eight domains. In addition, six visual analogue scales (VAS) evaluate disease-specific organ system symptoms: pain, digital ulcer, gastrointestinal, vascular, and pulmonary involvement, and overall disease severity, with scores standardised to a continuous scale from 0 (no symptoms) to 3 (worst symptoms).

Safety was assessed by the reporting of adverse events up to 1 day after study drug discontinuation and serious adverse events up to 28 days after study drug discontinuation. Liver function tests were performed at monthly intervals. Any marked laboratory abnormality was reported as an adverse event.

\section{Statistical methods}

Sample size selection was empirical for this open, single arm study. Statistical analyses were performed in an exploratory fashion. For numerical endpoints, the change from baseline is presented with $95 \%$ two-sided confidence intervals, based on asymptotic normality assumption. For dichotomous endpoints, the proportion of patients is provided with $95 \%$ two-sided CI, based on the binomial exact distribution. For time-to-event

Table 1 Demographics and patient characteristics at baseline

\begin{tabular}{|c|c|}
\hline Parameter & Value \\
\hline Male/female, $\mathrm{n}(\%)$ & $9(17 \%) / 44(83 \%)$ \\
\hline Age, years (mean (SD)) & 63 (13) (range 22-79) \\
\hline Weight, kg (mean (SD)) & 67 (13) (range 40-99) \\
\hline Caucasian/Asian & $51(96 \%) / 2(4 \%)$ \\
\hline \multicolumn{2}{|l|}{ Aetiology, n (\%): } \\
\hline Limited systemic sclerosis & $29(55 \%)$ \\
\hline Diffuse systemic sclerosis & $13(25 \%)$ \\
\hline Mixed connective tissue disease & $6(11 \%)$ \\
\hline Systemic lupus erythaematosus & $5(9 \%)$ \\
\hline Time from CTD diagnosis, weeks (mean (SD)) & 431 (503) (range 0-2227) \\
\hline Time from PAH diagnosis, weeks (mean (SD)) & 45 (66) (range 1-236) \\
\hline Signs of right heart failure, $\mathrm{n}(\%)$ & $8(15 \%)$ \\
\hline Patients with at least one digital ulcer, $n(\%)(n=50)$ & $15(30 \%)$ \\
\hline \multicolumn{2}{|l|}{ Right heart catheterisation: } \\
\hline $\begin{array}{l}\text { Mean pulmonary arterial pressure, } \mathrm{mmHg} \\
\text { (mean (SD)) }\end{array}$ & $39.5(12.6)$ \\
\hline Cardiac index, litres $/ \mathrm{min} / \mathrm{m}^{2}$ (mean $(\mathrm{SD}) ; \mathrm{n}=49$ ) & $2.9(0.9)$ \\
\hline $\begin{array}{l}\text { Mean pulmonary capillary wedge pressure, } \mathrm{mmHg} \\
\text { (mean (SD); } n=51 \text { ) }\end{array}$ & $10.1(4.4)$ \\
\hline $\begin{array}{l}\text { Pulmonary vascular resistance, dyn } / \mathrm{s} / \mathrm{cm}^{-5} \\
\text { (mean (SD); } \mathrm{n}=47 \text { ) }\end{array}$ & $559.4(371.5)$ \\
\hline Total lung capacity, \% (mean (SD); $n=46$ ) & $80.8(18.3)$ \\
\hline Forced vital capacity, \% of predicted (mean (SD)) & $85.9(23.6)$ \\
\hline \multicolumn{2}{|l|}{ Concomitant treatment, $\mathrm{n}(\%)$ : } \\
\hline Antithrombotic agents* & $41(77 \%)$ \\
\hline $\begin{array}{l}\text { Antacids/drug for treatment of peptic ulcer and } \\
\text { flatulence }\end{array}$ & $40(75 \%)$ \\
\hline Calcium channel blockers & $32(60 \%)$ \\
\hline Corticosteroids $\dagger$ & $30(57 \%)$ \\
\hline Diuretics & $28(53 \%)$ \\
\hline
\end{tabular}

Unless otherwise stated, $\mathrm{n}=53$.

*Mostly acenocoumarol, warfarin, or acetylsalicylic acid. †Mostly prednisolone. CTD, connective tissue disease; PAH, pulmonary arterial hypertension. 


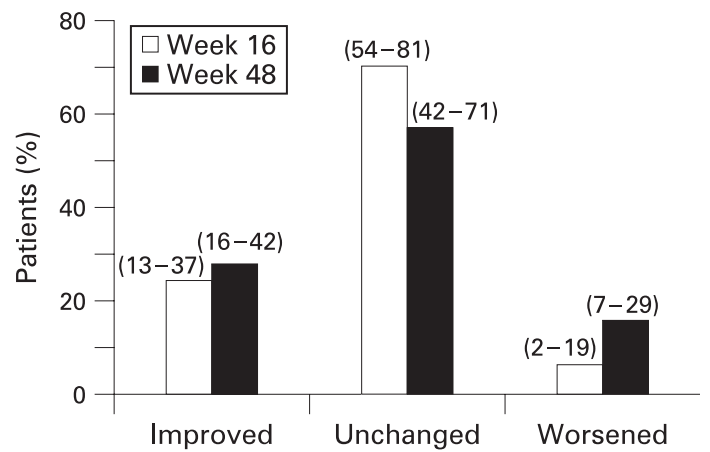

Figure 1 Improvement/worsening in World Health Organization (WHO) functional class at week 16 and week 48. Two patients at week 16 and three at week 48 were discontinued because of pulmonary arterial hypertension (PAH) worsening/death and were assigned WHO functional class IV at week 16 and week 48 , respectively, as per protocol. $(n=51)$. Confidence intervals (95\%) are indicated in brackets.

endpoints, Kaplan-Meier estimates are presented with 95\% two-sided CI calculated from Greenwood's formula. All treated patients were used for the survival analysis.

Values for missing assessments of WHO functional class, SF-36, and HAQ/VAS were derived by carrying forward the last observed post-baseline assessment. For patients who died, underwent lung transplantation, or discontinued study medication due to worsening of PAH prior to the considered timepoint (week 16 or week 48), the most conservative approach was used in case of missing assessment. The missing assessment was replaced with the worst value out of: (1) the last available postbaseline value observed for this patient, or (2) the worst value observed at the considered timepoint (ie, week 16 or week 48) over all other patients.

\section{RESULTS}

A total of 53 patients were treated over a 1-year period and received bosentan from July 2003 to August 2005. The median exposure to bosentan was 48.6 weeks (range 0.7 to 56.7 weeks). During the study, 17 patients (32\%) were prematurely discontinued from study treatment because of an adverse event $(\mathrm{n}=14,26 \%)$, sudden death $(\mathrm{n}=1,2 \%)$, disease progression ( $n=1,2 \%)$, or loss to follow-up ( $n=1,2 \%$ ). In total, 36 patients out of 53 completed the study.

\section{Patient demographics and disease characteristics}

Patient demographics and disease characteristics are presented in table 1 . The majority of patients were female and the mean (SD) age was 63 (13) years. Of 53 patients, 42 had SSc, 29 patients had limited and 13 patients had diffuse SSc. There were six patients with MCTD and five with SLE. Twelve patients had a history or evidence of lung fibrosis at baseline. In all but one of these cases was FVC greater than $60 \%$ of predicted.

\section{Concomitant corticosteroid therapy}

The numbers (percentages) of patients treated with prednisone or prednisolone included: 7 (54\%) patients with diffuse SSc (mean dose: $12.4 \mathrm{mg}$; range: $5-40 \mathrm{mg}$ ); 12 (41\%) patients with limited SSc (mean dose: $10.0 \mathrm{mg}$; range: $2.5-40 \mathrm{mg}$ ); 2 (40\%) patients with SLE (mean dose: $11.3 \mathrm{mg}$, range: $5-30 \mathrm{mg}$ ); and $6(100 \%)$ patients with MCTD (mean dose: $9.1 \mathrm{mg}$, range: $2.5-25 \mathrm{mg})$.

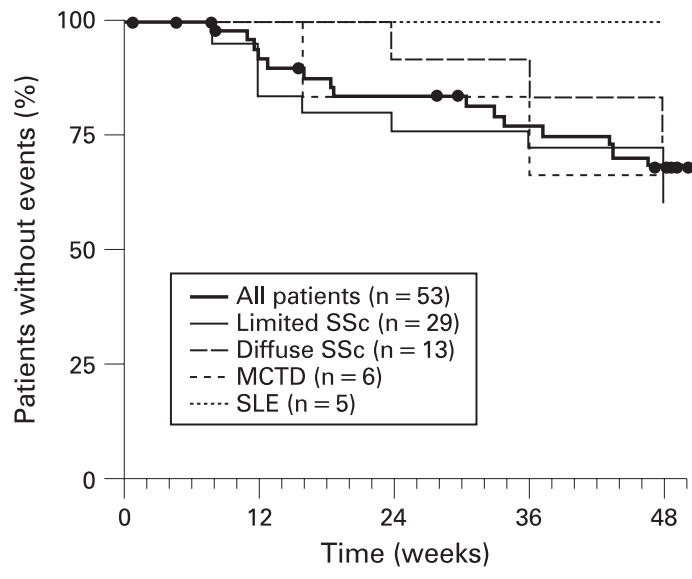

Figure 2 Kaplan-Meier estimates for time to clinical worsening, defined as the combined endpoint of death, hospitalisation due to pulmonary arterial hypertension (PAH) complications, use of epoprostenol or prostacyclin analogues for worsening of $\mathrm{PAH}$, lung transplantation, or discontinuation due to worsening of PAH. The KaplanMeier estimate was $88 \%$ (95\% $\mathrm{Cl} 79-97 \%$ ) at week 16, and $68 \%(95 \% \mathrm{Cl}$ $55-82 \%)$ at week 48.

\section{WHO functional class}

All patients were in WHO functional class III at baseline. At week 16, WHO class improved in 12 out of 51 patients (24\%), remained stable in 35 patients (69\%), and worsened in 4 patients (8\%). At week 48, it improved in 14 out of 51 patients (27\%), remained stable in 29 patients $(57 \%)$, and worsened in 8 patients (16\%) (fig 1).

\section{Clinical worsening}

Summary statistics on clinical worsening are shown in fig 2. The Kaplan-Meier estimate for the absence of clinical worsening was $88 \%$ at week 16 and $68 \%$ at week 48 . Interestingly, there was no clinical worsening among the five patients with SLE at week 48 whereas the estimate for the absence of clinical worsening was $75 \%, 67 \%$, and $61 \%$ for the patients with diffuse SSc, MCTD, and limited SSc, respectively. One patient received intravenous epoprostenol for 10 days during the course of the study.

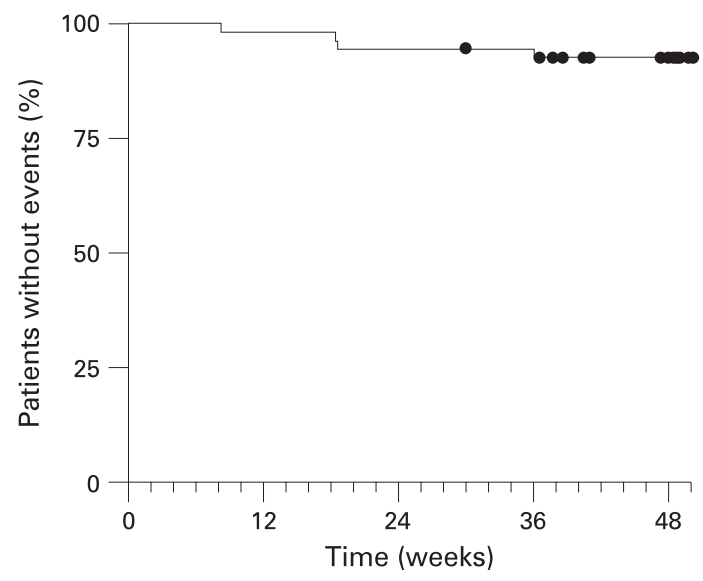

Figure 3 Kaplan-Meier estimates of survival (deaths occurring after treatment discontinuation for an adverse event were counted as an event). The Kaplan-Meier estimate was $92 \%$ (95\% Cl 85-100\%) at week 48. 
Table 2 Changes from baseline to week 48 in the Short Form Health Survey (SF-36) domain scores and health transition item

\begin{tabular}{|c|c|c|c|c|}
\hline & Baseline & Week 48 & Change & $95 \% \mathrm{Cl}$ \\
\hline \multicolumn{5}{|l|}{ Domain scores (norm-based) } \\
\hline Physical functioning* & $28.76(1.24)$ & $27.72(1.48)$ & $-1.04(1.37)$ & -3.79 to 1.71 \\
\hline Role, physical* & $27.47(2.15)$ & $26.19(1.89)$ & $-1.28(2.25)$ & -5.81 to 3.25 \\
\hline Pain & $43.00(1.55)$ & $41.92(1.74)$ & $-1.08(1.60)$ & -4.29 to 2.14 \\
\hline General health perception* & $33.89(1.24)$ & $32.42(1.24)$ & $-1.47(1.35)$ & -4.19 to 1.25 \\
\hline Vitality* $^{*}$ & $40.63(1.41)$ & $40.15(1.47)$ & $-0.49(1.32)$ & -3.15 to 2.17 \\
\hline Social functioning & $39.67(1.81)$ & $38.51(2.13)$ & $-1.16(2.26)$ & -5.70 to 3.38 \\
\hline Role, emotional $\dagger$ & $32.73(3.03)$ & $30.65(3.10)$ & $-2.07(3.65)$ & -9.43 to 5.29 \\
\hline Mental health* & $45.11(1.65)$ & $42.94(1.98)$ & $-2.17(1.63)$ & -5.45 to 1.11 \\
\hline Health transition item & $3.81(0.15)$ & $2.98(0.18)$ & $-0.83(0.22)$ & -1.27 to -0.39 \\
\hline \multicolumn{5}{|l|}{ Health transition item (n) } \\
\hline 1: Much better & 3 & 4 & & \\
\hline 2: Somewhat better & 2 & 17 & & \\
\hline 3: About the same & 6 & 9 & & \\
\hline 4: Somewhat worse & 26 & 10 & & \\
\hline 5: Much worse & 10 & 7 & & \\
\hline
\end{tabular}

\section{Survival}

The Kaplan-Meier estimates for the observed survival are presented in fig 3. Survival was $92 \%$ at week 48 . Four deaths were reported during the study: (1) sudden death, (2) staphylococcal sepsis as a result of ischemic colitis, (3) hyponatremia as a complication of high dose diuretics, including furosemide, and (4) exacerbated dyspnoea from worsening pulmonary fibrosis. These four patients had been diagnosed with limited SSc $(n=2)$, diffuse SSc $(n=1)$, and MCTD $(n=1)$. No patient with SLE died during the study.

\section{SF-36 and HAQ/VAS scores}

The SF-36 domain scores decreased minimally from baseline to week 48 . The self-evaluated health transition item at week 48 showed slightly more patients reporting improvement than patients reporting deterioration, in contrast to the baseline status. Accordingly, change in mean (SEM) value for this item was -0.83 (0.22) (95\% CI -1.27 to -0.39 ) (table 2). The HAO scores presented an overall increase at week 48 (table 3 ). The disability index was $1.17(0.11)$ at baseline and tended to increase at week $48(0.22(0.11))$. A similar mean increase was reported for all VAS scores at week 48, except for the lung score, which was stable on average (table 3 ).

\section{Safety}

The most frequent adverse events (\% patients) observed during the study were peripheral oedema (17\%), liver enzyme elevations $(17 \%$, of which $11 \%$ were specified as aminotransferase

Table 3 Changes from baseline to week 48 in the Health Assessment Questionnaire (HAO) and visual analogue scale (VAS) scores on a 0-3 scale

\begin{tabular}{lllll}
\hline & Baseline & Week 48 & Change & 95\% Cl \\
\hline HAO scores & & & & \\
Dressing & $1.15(0.16)$ & $1.49(0.19)$ & $0.34(0.16)$ & 0.01 to 0.67 \\
Arising & $0.77(0.13)$ & $1.09(0.17)$ & $0.32(0.20)$ & -0.08 to 0.72 \\
Eating & $0.81(0.13)$ & $0.98(0.17)$ & $0.17(0.16)$ & -0.16 to 0.50 \\
Walking & $1.32(0.14)$ & $1.60(0.18)$ & $0.28(0.16)$ & -0.05 to 0.60 \\
Hygiene & $0.98(0.15)$ & $1.30(0.19)$ & $0.32(0.18)$ & -0.04 to 0.68 \\
Reach & $1.28(0.16)$ & $1.62(0.18)$ & $0.34(0.16)$ & 0.01 to 0.67 \\
Grip & $1.15(0.17)$ & $1.28(0.18)$ & $0.13(0.17)$ & -0.22 to 0.48 \\
Activity & $1.94(0.14)$ & $1.98(0.17)$ & $0.04(0.14)$ & -0.23 to 0.32 \\
HAO disability index & $1.17(0.11)$ & $1.39(0.14)$ & $0.22(0.11)$ & -0.01 to 0.44 \\
VAS scores & & & & -0.13 to 0.51 \\
Pain & $0.87(0.11)$ & $1.06(0.13)$ & $0.19(0.16)$ & 0.0 to 0.46 \\
Gastrointestinal & $0.44(0.10)$ & $0.67(0.11)$ & $0.23(0.11)$ & -0.29 to 0.26 \\
Lung & $1.71(0.11)$ & $1.70(0.14)$ & $-0.02(0.14)$ & -0.18 to 0.60 \\
Vascular & $1.11(0.13)$ & $1.32(0.15)$ & $0.21(0.19)$ & -0.03 to 0.59 \\
Digital ulcer & $0.58(0.12)$ & $0.86(0.16)$ & $0.28(0.16)$ & -0.10 to 0.44 \\
Disease & $1.39(0.13)$ & $1.56(0.14)$ & $0.17(0.13)$ &
\end{tabular}

Values are mean (SEM), $n=47$. Five patients were discontinued because of pulmonary arterial hypertension (PAH) worsening/ death and were assigned the worst value observed over the analysis set at week 48 , as per protocol. A negative change corresponds to an improvement of the $\mathrm{HAO}$ and VAS scores. 
increases), diarrhoea (13\%), exacerbated dyspnoea (13\%), and nausea $(13 \%)$.

At least one serious adverse event was reported in $45 \%$ of patients (37 events in 24 patients). The most frequent serious adverse events were exacerbated dyspnoea (8\%) and pneumonia (8\%). All serious adverse events were judged unrelated to study medication by the investigators.

Overall, 14 patients (26\%) discontinued study medication because of an adverse event or serious adverse event. Discontinuations most often involved exacerbated dyspnoea $(6 \%)$, general physical health deterioration (6\%), and liver enzyme increase $(6 \%)$.

\section{DISCUSSION}

This is the first large multi-centre prospective single-arm study of survival and quality of life in PAH-CTD confirmed by right heart catheterisation. The results represent an important source of data on survival and quality of life in patients with PAHCTD treated with bosentan.

The survival estimate of $92 \%$ with only slight alteration in the patients' quality of life can be considered as a positive outcome in PAH-CTD, a progressive disease with very poor outcome in the absence of specific therapy. Treatment of PAH with bosentan was indicated in the patients included in this study. Hence, a placebo therapy for 48 weeks would have been unethical. The absence of a placebo group may be considered a limitation of the study, with concern that some of the improvements were due to "placebo" effect, rather than drug efficacy. However, non-subjective parameters, such as survival, cannot be explained by a placebo effect. Previously reported placebo-controlled PAH studies of bosentan or other PAH-specific treatments have not shown any clinically relevant improvements in placebo groups, in fact, they have generally shown a decline. ${ }^{13} 142021{ }^{35-37}$ In addition, a historical comparison shows that the observed estimate for absence of clinical worsening at week 16 is similar to the rates reported for the PAH-CTD patients treated with bosentan in the placebocontrolled BREATHE-1 study. ${ }^{21}$

The survival results of the study are in line with published data in patients treated with bosentan. In particular, the observed survival rate of $92 \%$ is comparable with the 1 -year survival of $86 \%$ reported by Denton et $a^{23}$ in a subgroup analysis of 64 patients with PAH-CTD (SSc, SLE, MCTD), who were enrolled in the two bosentan placebo-controlled PAH trials and the open-label extensions. Similarly, Williams et $a^{38}$ reported a survival at 1 year of $81 \%$ in a cohort of 45 patients with $\mathrm{PAH}$ related to SSc in class III-IV who were treated with bosentan as first line therapy. In contrast, the survival reported by these authors for the historical control (47 patients treated with basic therapy with $(n=27)$ or without $(n=20)$ prostanoids) was $68 \% .^{38}$ Data on the effects of injectable prostanoids and sildenafil on haemodynamics, exercise capacity and symptoms in PAH associated with connective tissue disease have been presented. ${ }^{39}{ }^{40}$ However, their effect has not been studied in a specific long-term cohort in this patient population..$^{41} 42$

The results of the study also suggest that bosentan improved or stabilised the clinical status of most patients with PAHCTD. In $84 \%$ of patients, the WHO functional class improved (27\%), or remained unchanged (57\%) at week 48.

The self-evaluated SF-36 health transition item showed more improvements than deteriorations in overall health perception at the end of the study, as well as an improvement in this overall perception compared to the year preceding the study. The decrease in SF-36 domain scores was lower than that generally considered as the minimal clinically important difference. ${ }^{43}$ The apparent discrepancy between the encouraging results of the SF-36 health transition item and the decrease in the domain scores can be explained by the different nature of these measures. Whereas the health transition item is a general and relative (compared to 1 year ago) measure, the domain scores are specific and absolute (providing a value at the date of assessment) measures.

Patients included in the current study had moderate-to-severe baseline disabilities $^{44}$ (HAO disability index $=1.17$ (0.11)). At week 48 , the observed mean increases in the HAQ disability index ( $+0.22,95 \% \mathrm{CI}-0.01$ to 0.44$)$ reached the minimal clinical important difference value reported for patients with SSc $(0.10$ $0.22)^{45} 46$ and the VAS scores increased by less than 0.3 units, except for the lung score which was stable. Interpretation of these findings is limited by the absence of a control group. In a different cohort of SSc patients without PAH followed for a mean of 1.8 years, the HAO disability index increased by 0.4 units and VAS scores by $0.5-0.6$ despite state of the art therapy. ${ }^{47}$ Hence, our findings suggest that bosentan $\mathrm{PAH}$ therapy was specifically associated with a stabilisation of the lung score despite other coexisting CTD respiratory manifestations, but, as expected, had less impact on other organ-related quality of life indicators.

As for any instrument, the HAQ/VAS and SF-36 tools have well known limitations: the patients' judgments about the extent of their disabilities may show marked individual variation, ${ }^{48}$ the HAO/VAS does not capture the psychological distress felt by patients with PAH and/or CTDs, ${ }^{49}{ }^{50}$ and neither instrument is specific for PAH. Consequently, they may have limited sensitivity in detecting changes in quality of life resulting from PAH treatment over time. ${ }^{51}$ New instruments, which were not available at the start of this study, such as the Cambridge Pulmonary Hypertension Outcome Review (CAMPHOR) $^{51}$ have been developed from qualitative, unstructured interviews with PAH patients and are expected to provide a more accurate assessment of the impact of PAH on quality of life, when validated translations permit their use in international studies.

The minimum TLC for inclusion in our study was $50 \%$ of predicted. Low TLC may reflect interstitial lung disease or chest wall restriction or other cause for low lung volumes such as pleural disease. There was evidence of lung fibrosis in some cases but our experience and previously published data ${ }^{52} 53$ suggest that outcome is especially poor in CTD cases, particularly SSc, in which there is RHC proven pulmonary hypertension together with lung fibrosis. Hence, the inclusion of these patients would be more likely to have had a negative impact on the overall prognosis in the cohort.

In conclusion, our study suggests that patients with PAHCTD can be treated with bosentan in centres having PAH in addition to CTD expertise and that bosentan is effective for the treatment of this patient population. Our results suggest that bosentan improves or stabilises the clinical status in the majority of PAH-CTD patients and, most importantly, has a positive impact on survival. In contrast to the observed changes of SF-36 and HAQ scores not related to PAH, the HAO lung VAS score stabilised and the SF-36 health transition item improved. Altogether, these results are consistent with sustained benefit in this patient population, which is usually characterised by a high morbidity and mortality. 
Acknowledgements: The authors would like to acknowledge the collaboration and commitment of all the local investigators and their staff: Belgium: Marion Delcroix, UZ Gasthuisberg, Leuven. France: Philippe Humbert, Hôpital Saint-Jacques, Besançon. Roland Jaussaud, Hôpital Robert Debré, Reims. Pascal Roblot, CHRU La Miletrie, Poitiers. Bernard Lorcerie, CHU Bocage, Dijon. Xavier Puechal, Le Mans. Germany: Michael Buslau, Sanitas Alpenklinik Inzell GmbH. Klaus Helmke, Krankenhaus München Bogenhausen, München. Ulf Müller-Ladner, Universitätsklinikum Regensburg, Regensburg. Italy: Francesco Trotta, Università degli Studi di Ferrara, Ferrara. Netherlands: Hendrika Bootsma, Academisch Ziekenhuis Groningen, Groningen. Pieter Van Paassen, Academisch Ziekenhuis Maastricht, Maastricht. Norway: Jan Tore Gran, Rikshospitalet, Oslo. Spain: Ana Prost, Hospital del Mar, Barcelona. Javier Orte, Hospital Ramon y Cajal, Madrid. José Roman, Hospital Dr Peset, Valencia.

Funding: The study was supported by an investigational grant from Actelion Pharmaceuticals Ltd. The database was retained by the sponsor, but the investigators had access to the complete database. The statistical analysis was performed by a statistician who is an employee of the sponsoring company and is listed among the authors (AM): the manuscript was reviewed and approved by the academic authors. The academic authors assume full responsibility for the completeness and accuracy of the content of the manuscript. Grant support: This research was supported by Actelion Pharmaceuticals Ltd.

Competing interests: CPD has been a consultant to, or received research grants from the following companies: Genzyme Corporation, Actelion Pharmaceuticals, Aspreva Pharmaceuticals, Encysive Corporation, DigNa Pharmaceuticals. JJEP, H-HP, $A G, G R, S D e V$ have no significant industry affiliation (all under 10000 USD). AB has received speaking fees or consultancy fees from GSK, Actelion Pharmaceuticals and Pfizer less than 2K US\$. AB's employing Institution is involved in contract research for GSK, Actelion Pharmaceuticals, Pfizer, United Therapeutics, Encysive, Myogen, Merck. $A B$ 's employing Institution's research foundation has received unrestricted educational grants from GSK and Actelion Pharmaceuticals. FHJvdH is a consultant for Bristol Myers Squibb (BMS) and Abbott. LG is a consultant for Actelion Pharmaceuticals (advisory boards) and a member of the scientific council of Actelion France. AM, MD and $\mathrm{OB}$ are employees of Actelion Pharmaceuticals.

\section{REFERENCES}

1. Mukerjee D, St George D, Coleiro B, Knight C, Denton CP, Davar J, et al. Prevalence and outcome in systemic sclerosis associated pulmonary arterial hypertension: application of a registry approach. Ann Rheum Dis 2003;62:1088-93.

2. Simonson JS, Schiller NB, Petri M, Hellmann DB. Pulmonary hypertension in systemic lupus erythematosus. J Rheumatol 1989;16:918-25.

3. Prakash UB. Respiratory complications in mixed connective tissue disease. Clin Chest Med 1998;19:733-46.

4. Gescuk BD, Davis JC Jr. Novel therapeutic agents for systemic lupus erythematosus. Curr Opin Rheumatol 2002;14:515-21.

5. Denton CP, Black CM. Novel therapeutic strategies in scleroderma. Curr Rheumatol Rep 1999;1:22-7.

6. Hachulla E, Gressin V, Guillevin L, Carpentier P, Diot E, Sibilia J, et al. Early detection of pulmonary arterial hypertension in systemic sclerosis: a French nationwide prospective multicenter study. Arthritis Rheum 2005;52:3792-800.

7. Shen JY, Chen SL, Wu YX, Tao RQ, Gu YY, Bao CD, et al. Pulmonary hypertension in systemic lupus erythematosus. Rheumatol Int 1999;18:147-51.

8. Pan TL, Thumboo J, Boey ML. Primary and secondary pulmonary hypertension in systemic lupus erythematosus. Lupus 2000:9:338-42.

9. Denton CP, Black CM. Pulmonary hypertension in systemic sclerosis. Rheum Dis Clin North Am 2003;29:335-49.

10. Hachulla $\mathbf{E}$, Coghlan JG. A new era in the management of pulmonary arterial hypertension related to scleroderma: endothelin receptor antagonism. Ann Rheum Dis 2004:63:1009-14.

11. Coghlan JG, Handler C. Connective tissue associated pulmonary arterial hypertension. Lupus 2006;15:138-42.

12. Badesch DB, Tapson VF, McGoon MD, Brundage BH, Rubin LJ, Wigley FM, et al. Continuous intravenous epoprostenol for pulmonary hypertension due to the scleroderma spectrum of disease. A randomized, controlled trial. Ann Intern Med 2000;132:425-34.

13. Simonneau G, Barst RJ, Galie N, Naeije R, Rich S, Bourge RC, et al. Continuous subcutaneous infusion of treprostinil, a prostacyclin analogue, in patients with pulmonary hypertension. Am J Respir Crit Care Med 2002;165:1-5.

14. Olschewski H, Simonneau G, Galie N, Higenbottam T, Naeije R, Rubin LJ, et al. Inhaled iloprost for severe pulmonary hypertension. N Engl J Med 2002;347:322-9.

15. Robbins IM, Gaine SP, Schilz R, Tapson VF, Rubin LJ, Loyd JE. Epoprostenol for treatment of pulmonary hypertension in patients with systemic lupus erythematosus. Chest 2000;117:14-8

16. Stupi AM, Steen VD, Owens GR, Barnes EL, Rodnan GP, Medsger TA Jr. Pulmonary hypertension in the CREST syndrome variant of systemic sclerosis. Arthritis Rheum 1986;29:515-24

17. Cervera R, Khamashta MA, Font J, Sebastiani GD, Gil A, Lavilla P, et al. Morbidity and mortality in systemic lupus erythematosus during a 5-year period. A multicenter prospective study of 1,000 patients. European Working Party on Systemic Lupus Erythematosus. Medicine (Baltimore) 1999:78:167-75.
18. Koh ET, Lee P, Gladman DD, Abu-Shakra M. Pulmonary hypertension in systemic sclerosis: an analysis of 17 patients. Br J Rheumatol 1996;35:989-93.

19. Kawut SM, Taichman DB, Archer-Chicko CL, Palevsky HI, Kimmel SE. Hemodynamics and survival in patients with pulmonary arterial hypertension related to systemic sclerosis. Chest 2003;123:344-50.

20. Channick RN, Simonneau G, Sitbon O, Robbins IM, Frost A, Tapson VF, et al. Effects of the dual endothelin-receptor antagonist bosentan in patients with pulmonary hypertension: a randomised placebo-controlled study. Lancet 2001;358:1119-23

21. Rubin LJ, Badesch DB, Barst RJ, Galie N, Black CM, Keogh A, et al. Bosentan therapy for pulmonary arterial hypertension. N Engl J Med 2002;346:896-903.

22. Sitbon 0, Badesch DB, Channick RN, Frost A, Robbins IM, Simonneau G, et al. Effects of the dual endothelin receptor antagonist bosentan in patients with pulmonary arterial hypertension: a 1-year follow-up study. Chest 2003;124:247-54.

23. Denton CP, Humbert M, Rubin L, Black CM. Bosentan treatment for pulmonary arterial hypertension related to connective tissue disease: a subgroup analysis of the pivotal clinical trials and their open-label extensions. Ann Rheum Dis 2006;65:1336-40.

24. Keogh AM, McNeil KD, Wlodarczyk J, Gabbay E, Williams TJ. Quality of life in pulmonary arterial hypertension: improvement and maintenance with bosentan. J Heart Lung Transplant 2007;26:181-7.

25. British Cardiac Society. Recommendations on the management of pulmonary hypertension in clinical practice. Heart 2001;86(Suppl 1):i1-i13.

26. Barst RJ, McGoon M, Torbicki A, Sitbon 0, Krowka MJ, Olschewski H, et al. Diagnosis and differential assessment of pulmonary arterial hypertension. J Am Coll Cardiol 2004:43(12 Suppl S):40S-47S.

27. Ware JE Jr, Sherbourne CD. The MOS 36-item short-form health survey (SF-36). I. Conceptual framework and item selection. Med Care 1992;30:473-83.

28. Steen VD, Medsger TA Jr. The value of the Health Assessment Questionnaire and special patient-generated scales to demonstrate change in systemic sclerosis patients over time. Arthritis Rheum 1997:40:1984-91

29. Khanna D, Furst DE, Clements PJ, Park GS, Hays RD, Yoon J, et al. Responsiveness of the SF-36 and the Health Assessment Questionnaire Disability Index in a systemic sclerosis clinical trial. J Rheumatol 2005;32:832-40.

30. Danieli E, Airo P, Bettoni L, Cinquini M, Antonioli CM, Cavazzana I, et al. Healthrelated quality of life measured by the Short Form 36 (SF-36) in systemic sclerosis: correlations with indexes of disease activity and severity, disability, and depressive symptoms. Clin Rheumatol 2005;24:48-54.

31. Poole JL, Steen VD. The use of the Health Assessment Questionnaire (HAO) to determine physical disability in systemic sclerosis. Arthritis Care Res 1991;4:27-31.

32. Silman A, Akesson A, Newman J, Henriksson H, Sandquist G, Nihill M, et al. Assessment of functional ability in patients with scleroderma: a proposed new disability assessment instrument. J Rheumatol 1998;25:79-83.

33. Saba J, Quinet RJ, Davis WE, Krousel-Wood M, Chambers R, Gomez N, et al. Inverse correlation of each functional status scale of the SF-36 with degree of disease activity in systemic lupus erythematosus (m-SLAM). Joint Bone Spine 2003;70:348-51.

34. Hochberg MC, Sutton JD. Physical disability and psychosocial dysfunction in systemic lupus erythematosus. J Rheumatol 1988;15:959-64.

35. Barst RJ, Rubin LJ, Long WA, McGoon MD, Rich S, Badesch DB, et al. A comparison of continuous intravenous epoprostenol (prostacyclin) with conventional therapy for primary pulmonary hypertension. The Primary Pulmonary Hypertension Study Group. N Engl J Med 1996;334:296-302.

36. Oudiz RJ, Schilz RJ, Barst RJ, Galie N, Rich S, Rubin LJ, et al. Treprostinil, a prostacyclin analogue, in pulmonary arterial hypertension associated with connective tissue disease. Chest 2004;126:420-7.

37. Sastry BK, Narasimhan C, Reddy NK, Raju BS. Clinical efficacy of sildenafil in primary pulmonary hypertension: a randomized, placebo-controlled, double-blind, crossover study. J Am Coll Cardiol 2004;43:1149-53.

38. Williams MH, Das C, Handler CE, Akram MR, Davar J, Denton CP, et al. Systemic sclerosis associated pulmonary hypertension: improved survival in the current era. Heart 2006;92:926-32

39. Galie N, Ghofrani HA, Torbicki A, Barst RJ, Rubin LJ, Badesch D, et al. Sildenafil citrate therapy for pulmonary arterial hypertension. N Engl J Med 2005;353:2148-57.

40. Strauss WL, Edelman JD. Prostanoid therapy for pulmonary arterial hypertension. Clin Chest Med 2007:28:127-42.

41. Galie N, Manes A, Farahani KV, Pelino F, Palazzini M, Negro L, et al. Pulmonary arterial hypertension associated to connective tissue diseases. Lupus 2005;14:713-7.

42. Allanore $\mathbf{Y}$, Avouac J, Wipff J, Kahan A. New therapeutic strategies in the management of systemic sclerosis. Expert Opin Pharmacother 2007;8:607-15

43. Strand V, Crawford B. Improvement in health-related quality of life in patients with SLE following sustained reductions in anti-dsDNA antibodies. Expert Rev Pharmacoeconom Outcome Res 2005;5:317-26.

44. Clements PJ, Wong WK, Hurwitz EL, Furst DE, Mayes M, White B, et al. The Disability Index of the Health Assessment Questionnaire is a predictor and correlate of outcome in the high-dose versus low-dose penicillamine in systemic sclerosis trial. Arthritis Rheum 2001:44:653-61.

45. Bruce B, Fries JF. The Stanford Health Assessment Questionnaire: a review of its history, issues, progress, and documentation. J Rheumatol 2003;30:167-78.

46. Khanna D, Furst DE, Hays RD, Park GS, Wong WK, Seibold JR, et al. Minimally important difference in diffuse systemic sclerosis: results from the D-penicillamine study. Ann Rheum Dis 2006:65:1325-9.

47. Serednicka K, Smyth AE, Black CM, Denton CP. Using a self-reported functional score to assess disease progression in systemic sclerosis. Rheumatology (Oxford) 2007:46:1107-10. 
48. Scott DL, Smith C, Kingsley G. Joint damage and disability in rheumatoid arthritis: an updated systematic review. Clin Exp Rheumatol 2003;21(5 Suppl 31):S20-7.

49. Angelopoulos NV, Drosos AA, Moutsopoulos HM. Psychiatric symptoms associated with scleroderma. Psychother Psychosom 2001;70:145-50.

50. Del Rosso A, Boldrini M, D'Agostino D, Placidi GP, Scarpato A, Pignone A, et al. Health-related quality of life in systemic sclerosis as measured by the Short Form 36: relationship with clinical and biologic markers. Arthritis Rheum 2004;51:475-81.
51. McKenna SP, Doughty N, Meads DM, Doward LC, Pepke-Zaba J. The Cambridge Pulmonary Hypertension Outcome Review (CAMPHOR): a measure of health-related quality of life and quality of life for patients with pulmonary hypertension. Qual Life Res 2006:15:103-15.

52. Denton CP, Black CM. Scleroderma and related disorders: therapeutic aspects. Baillieres Best Pract Res Clin Rheumatol 2000;14:17-35.

53. Bolster MB, Silver RM. Lung disease in systemic sclerosis (scleroderma). Baillieres Clin Rheumatol 1993;7:79-97.

Use the "My folders" feature to save and organise articles you want to return to quickly—saving space on your hard drive. You can also save searches, which will save you time. You will only need to register once for this service, which can be used for this journal or all BMJ Journals, including the BMJ. 